\title{
Selecting an optimal mixed products using grey relationship model
}

\author{
Farshad Faezy Razi*, Abolfazl Danaei, Amir Ehsani and Changiz Dolati
}

Department of Management, Semnan Branch, Islamic Azad University, Semnan, Iran

\begin{tabular}{|c|c|}
\hline C HRON I C L E & A B S T R A T \\
\hline $\begin{array}{l}\text { Article history: } \\
\text { Received January } 12,2013 \\
\text { Received in revised format } \\
15 \text { April } 2013 \\
\text { Accepted } 26 \text { April } 2013 \\
\text { Available online } \\
\text { April } 282013 \\
\text { Keywords: } \\
\text { Mixed product } \\
\text { Supply chain management }\end{array}$ & $\begin{array}{l}\text { This paper presents an integrated supplier selection and inventory management using grey } \\
\text { relationship model (GRM) as well as multi-objective decision making process. The proposed } \\
\text { model of this paper first ranks different suppliers based on GRM technique and then determines } \\
\text { the optimum level of inventory by considering different objectives. To show the } \\
\text { implementation of the proposed model, we use some benchmark data presented by Talluri and } \\
\text { Baker [Talluri, S., \& Baker, R. C. (2002). A multi-phase mathematical programming approach } \\
\text { for effective supply chain design. European Journal of Operational Research, 141(3), 544-558.]. } \\
\text { The preliminary results indicate that the proposed model of this paper is capable of handling } \\
\text { different criteria for supplier selection. }\end{array}$ \\
\hline
\end{tabular}

\section{Introduction}

Initial buying decisions such as make-or-buy decisions and supplier selection are considered as the most important strategies for companies. The nature of these decisions usually maintains a complex framework and managerial decisions play essential role on making appropriate long-term decisions. Nevertheless, the application of outranking techniques in purchasing decisions has not been reviewed, extensively (Weber et al., 1991; Wray et al., 1994). De Boer et al. (1998) demonstrated through means of a supplier selection instance, that an outranking approach could be very well suited as a decision-making tool for initial purchasing decisions. De Boer et al. (2001) presented a comprehensive review of decision methods reported in the literature for supporting the supplier selection process. They positioned the contributions in a framework that takes the diversity of procurement situations based on complexity and relative importance and covered all phases in the supplier selection process.

*Corresponding author. Tel: +989124258951

E-mail addresses: farshadfaezy @yahoo.com (F. Faezy Razi)

(C) 2013 Growing Science Ltd. All rights reserved. doi: $10.5267 /$ j.msl.2013.04.027 
Saen (2008) argued that supplier-selection models used be ranked solely based on cardinal data with less emphasis on ordinal data. However, with the widespread use of manufacturing philosophies such as just-in-time (JIT), emphasis had shifted to the concurrent consideration of cardinal and ordinal data in the supplier-selection process. They explained that the application of data envelopment analysis (DEA) for supplier-selection problems rely on total flexibility of the weights. They proposed a pair of assurance region-imprecise data envelopment analysis (AR-IDEA) technique for choosing the best suppliers in the presence of both weight restrictions and imprecise data. Saen (2009) presented a decision model for ranking suppliers in the presence of cardinal and ordinal data, weight restrictions, and nondiscretionary factors.

Ghodsypour and O'brien (2001) presented a mixed integer non-linear programming model to handle the multiple sourcing problem, which takes into account the total cost of logistics, including net price, storage, transportation and ordering costs. Kahraman et al. (2003) implemented fuzzy analytic hierarchy process (AHP) to choose the best supplier company providing the most satisfaction for the criteria detected. According to Min (1994), international supplier selection is one of the most complicated and risky owing to a variety of uncontrollable and unpredictable factors influencing the decision. These factors may incorporate political situations, tariff barriers, cultural and communication barriers, trade regulations and agreements, currency exchange rates, cultural differences, ethical standards, quality standards and so forth (Pan, 1989; Rosenthal et al., 1995).

Noorul Haq and Kannan (2006) designed of an integrated supplier selection and multi-echelon distribution inventory model in a built-to-order supply chain environment. Their work dealt with the development of an integrated supplier selection and multi-echelon distribution inventory model (MEDIM) for the original equipment manufacturing firm in a built-to-order supply chain environment based on fuzzy analytical hierarchy process (FAHP) and a genetic algorithm. The primary objective of their work was to design the integrated qualitative decision-making of the supplier selection model using FAHP with that of the quantitative mathematical model for the distribution inventory supply chain using a metaheuristics method.

Pi and Low (2006) proposed a method for supplier evaluation and selection via Taguchi loss functions and an AHP. Shin et al. (2000) investigated the effect of a supply management orientation (SMO) on the suppliers' operational performance and buyers' competitive priorities including cost, quality, delivery, flexibility. Talluri and Baker (2002) presented a multi-phase mathematical programming approach for effective supply chain design. Wang et al. (2004) integrated product characteristics to supply chain strategy and adopted supply chain operations reference (SCOR) model level I performance metrics as the decision criteria. They also developed an integrated analytic hierarchy process (AHP) and preemptive goal programming (PGP) based multi-criteria decisionmaking methodology to consider both qualitative and quantitative factors in supplier selection. Wangphanich et al. (2010) presented an analysis of the bullwhip effect in multi-product, multi-stage supply chain systems-a simulation approach. Wu (2002) presented a comparative study of using grey relational analysis in multiple attribute decision making problems.

\section{The proposed model}

\subsection{Grey Model}

The proposed model of this paper considers six major factors for supplier selection including purchasing expenditure, quality of product, on time delivery, customer services, partnership and financial strength. The first factor, purchasing expenditure consists of three factors including product price, transportation and ordering cost. The second factor, quality consists of three factors, which are the ratio of waste materials, returned items and quality of system. The third item, on time delivery, includes two items of time delay and quantity shortage. Customer services include three options of being responsive, time of response and the way of meeting customers' requests. Partnership is another important factor including partnership in plans or in contracts. Finally, financial strength is 
the last item, which includes three sub-item including working capital, revenue and cash flow. The proposed model of this paper uses grey relation model (GRM) originally developed by Deng (1989). The method consists of the following steps,

Step 1: In this step, we compute total value of each alternative and normalize them based. Let $m$ and $n$ be alternative and attribute, therefore, we have,

$$
\begin{aligned}
& X_{0}=\left(x_{01}, x_{02}, \ldots, x_{0 n}\right) \\
& X_{i}=\left(x_{i 1}, x_{12}, \ldots, x_{i n}\right)
\end{aligned}
$$

Let $y_{i}$ be the value of each alternative, therefore we have,

$$
Y i=\left(y_{i 1}, y_{i 2, \ldots,} y_{i n}\right) \text {, }
$$

where $y_{i j}$ is the value of attribute $i$ on alternative $j$. The consistency ratio of $x_{i j}=\left(x_{i 1}, x_{i 2}, \ldots, x_{i n}\right)$ is calculated based on the following,

$X_{i}(j)^{*}=\frac{x_{i}(j)-\min x_{i}(j)}{\max x_{i}(j)-\min x_{i}(j)}$

$X_{i}(j)^{*}=\frac{\max x_{i}(j)-x_{i}(j)}{\max x_{i}(j)-\min x_{i}(j)}$

$X_{i j}=\frac{\left|x_{i}(j)-x_{0 b}(j)\right|}{\max x_{i}(j)-x_{0 b}(j)}$

Step 2. Define the reference value as follows,

$X_{0}=\left(x_{01}, x_{02}, \ldots, x_{0 n}\right)=(1,1, \ldots, 1)$

Step 3. Calculate confidence interval

$Y\left(x_{0 j}, x_{i j}\right)=\frac{\Delta_{\min +\xi} \Delta_{\max }}{\Delta_{i j+\xi} \Delta_{\max }}$

where $\Delta_{i j}$ is calculated as follows,

$\Delta_{i j}=\left|x_{0 j}-x_{i j}\right|$.

In addition, $\Delta_{\min }$ and $\Delta_{\max }$ are calculated as follows,

$\Delta_{\min }=\min \left\{\Delta_{i j}, i=1, \ldots, m, j=1, \ldots, n\right\}$

$\Delta_{\max }=\max \left\{\Delta_{i j}, i=1, ., m, j=1, \ldots, n\right\}$

Step 4. Calculate grey value

$$
\Gamma=\sum_{j=1}^{n} w_{j} Y\left(X_{0 j}, X_{i j}\right) \times\left(X_{0 j}, X_{i j}\right)
$$

The weights used in Eq. (12) are determined using analytical hierarchy process (AHP).

\subsection{Supply chain model}

In this section, we present a multi-objective decision making where three objectives of ordering cost, delivery time and quality are considered. 
$\min z_{1}=\sum_{i=1}^{m} \sum_{j=1}^{n} c_{i j} x_{i j}$,

where $c_{i j}$ is transportation cost for delivering $j^{\text {th }}$ item from resource $i$ and it consists of three components of purchasing cost $\left(p_{i j}\right)$, transportation expenditure $\left(F_{i j}\right)$ and ordering cost $\left(O_{i j}\right)$, respectively.

\subsubsection{Cost of quality}

Let $d_{i j}$ be the sum of the number of returned and waste materials for delivering $j^{\text {th }}$ item from resource $i$. Therefore, we have,

$$
\min z_{2}=\sum_{i=1}^{m} \sum_{j=1}^{n} d_{i j} x_{i j}
$$

\subsubsection{On time delivery}

Let $t_{i j}$ be the delivery time of $j^{\text {th }}$ item from resource $i$. Therefore, we have,

$$
\min z_{3}=\sum_{i=1}^{m} \sum_{j=1}^{n} t_{i j} x_{i j}
$$

\subsubsection{Budget constraint}

The next constraint is associated with the amount of budget for ordering goods as follows,

$$
\sum_{i=1}^{m} p_{i j} x_{i j} \leq \beta_{j}, j=1, \cdots, n
$$

\subsubsection{Demand constraint}

The next constraint is associated with demand $\left(D_{j}\right)$ for ordering goods as follows,

$$
\sum_{i=1}^{m} x_{i j} \leq D_{j}, j=1, \cdots, n
$$

\subsubsection{Supply constraint}

Supply constraints are stated as follows,

$\sum_{i=1}^{m} x_{i j} \geq S_{j}, j=1, \cdots, n$

\subsubsection{Waste constraint}

Let $Q_{i j}$ be the amount of waste reported for $j^{\text {th }}$ item from resource $i$. In addition, let $\alpha_{i}$ be the amount of allowable waste purchased from each supplier. Therefore, we have,

$$
\sum_{i=1}^{m} Q_{i j} x_{i j} \geq \alpha_{i} D_{j}, j=1, \cdots, n
$$

\subsubsection{Inventory constraint}

Let $A_{j}$ and $L_{j}$ be the average amount of inventory and lead time for product $j$ item. In addition, let $I_{i}^{0}$ be the amount of inventory at the beginning of each period. Therefore, we have, 
$\sum_{i=1}^{m} x_{i j} \geq L_{i} A_{j}-I_{i}^{0}, j=1, \cdots, n$

\subsection{A mixed integer programming approach}

The proposed mixed integer programming approach uses grey technique to choose appropriate suppliers. Let $y_{i}$ be an integer variable, which is one when supplier $j$ is selected and zero, otherwise. Therefore, we propose a new objective function as follows,

$\max z_{0}=\sum_{i=1}^{m} \sum_{j=1}^{n} w_{j} y_{i}$,

where $w_{j}$ is the relative weight of supplier $j$ obtained using grey technique. Therefore, the first objective function specified in Eq. (13) is stated as follows,

$$
\min z_{1}=\sum_{i=1}^{m} \sum_{j=1}^{n}\left(p_{i j} x_{i j}+F_{i j} y_{i}+O_{i j} y_{i}\right)
$$

In addition, the supply constraint is also defined as follows,

$$
\sum_{i=1}^{m} x_{i j} \geq S_{i j} y_{i}, j=1, \cdots, n
$$

The other constrains hold for the new mixed integer programming problem as stated earlier.

\section{The case study}

The proposed model of this paper uses the data from the literature (Talluri \& Baker, 2002). Table 1 shows the input data where D represents the distance, SR indicates the supplier credit, TC specifies the total cost, NB is the total number of orders received from the supplier with no error, NOT represents the total number of on time delivery and SV specifies the number of parts.

\section{Table 1}

\begin{tabular}{|c|c|c|c|c|c|c|}
\hline & $\mathrm{TC}$ & SR & D & NOT & NB & $\mathrm{SV}$ \\
\hline S1 & 253 & 5 & 249 & 187 & 90 & 2 \\
\hline S2 & 268 & 10 & 643 & 194 & 130 & 13 \\
\hline S3 & 259 & 3 & 714 & 220 & 200 & 3 \\
\hline S4 & 180 & 6 & 1809 & 160 & 100 & 3 \\
\hline S5 & 257 & 4 & 238 & 204 & 173 & 24 \\
\hline S6 & 248 & 2 & 241 & 192 & 170 & 28 \\
\hline S7 & 272 & 8 & 1404 & 194 & 60 & 1 \\
\hline S8 & 330 & 11 & 984 & 195 & 145 & 24 \\
\hline S9 & 327 & 9 & 641 & 200 & 150 & 11 \\
\hline S10 & 330 & 7 & 588 & 171 & 90 & 53 \\
\hline S11 & 321 & 16 & 241 & 174 & 100 & 10 \\
\hline S12 & 329 & 14 & 567 & 209 & 200 & 7 \\
\hline S13 & 281 & 15 & 567 & 165 & 163 & 19 \\
\hline S14 & 309 & 13 & 967 & 199 & 170 & 12 \\
\hline S15 & 291 & 12 & 635 & 188 & 185 & 33 \\
\hline S16 & 334 & 17 & 795 & 168 & 85 & 2 \\
\hline S17 & 249 & 1 & 689 & 177 & 130 & 34 \\
\hline $\mathrm{S} 18$ & 216 & 18 & 913 & 167 & 160 & 9 \\
\hline Index & 180 & 18 & 238 & 220 & 200 & 53 \\
\hline
\end{tabular}

The input number for the case study of the proposed model

Note that the last row of Table 1 represents the $\min / \max$ of the numbers from each column, which is used in Step 1 of the proposed model. Therefore, we have $X_{0}=(180,18,238,220,200,53)$. Table 2 demonstrates details of the implementation of the second step of GRM method as follows, 
Table 2

The results of the second step of the proposed GRM method

\begin{tabular}{|c|c|c|c|c|c|c|}
\hline & $\mathrm{TC}(-)$ & $\mathrm{SR}(+)$ & $\mathrm{D}(-)$ & $\operatorname{NOT}(+)$ & $\mathrm{NB}(+)$ & $\mathrm{SV}(+)$ \\
\hline $\mathrm{s} 1$ & 0.525974 & 0.235294 & 0.992998 & 0.45 & 0.214286 & 0.019231 \\
\hline s2 & 0.428571 & 0.529412 & 0.742202 & 0.566667 & 0.5 & 0.230769 \\
\hline s3 & 0.487013 & 0.117647 & 0.697008 & 1 & 1 & 0.038462 \\
\hline s4 & 1 & 0.294118 & 0 & 0 & 0.285714 & 0.038462 \\
\hline s5 & 0.5 & 0.176471 & 1 & 0.733333 & 0.807143 & 0.442308 \\
\hline s6 & 0.558442 & 0.058824 & 0.99809 & 0.533333 & 0.785714 & 0.519231 \\
\hline s7 & 0.402597 & 0.411765 & 0.257798 & 0.566667 & 0 & 0 \\
\hline s8 & 0.025974 & 0.588235 & 0.525143 & 0.583333 & 0.607143 & 0.442308 \\
\hline s9 & 0.045455 & 0.470588 & 0.743475 & 0.666667 & 0.642857 & 0.192308 \\
\hline $\mathrm{s} 10$ & 0.025974 & 0.352941 & 0.777212 & 0.183333 & 0.214286 & 1 \\
\hline s11 & 0.084416 & 0.882353 & 0.99809 & 0.233333 & 0.285714 & 0.173077 \\
\hline $\mathrm{s} 12$ & 0.032468 & 0.764706 & 0.790579 & 0.816667 & 1 & 0.115385 \\
\hline s 13 & 0.344156 & 0.823529 & 0.790579 & 0.083333 & 0.735714 & 0.346154 \\
\hline s14 & 0.162338 & 0.705882 & 0.535964 & 0.65 & 0.785714 & 0.211538 \\
\hline $\mathrm{s} 15$ & 0.279221 & 0.647059 & 0.747295 & 0.466667 & 0.892857 & 0.615385 \\
\hline s16 & 0 & 0.941176 & 0.645449 & 0.133333 & 0.178571 & 0.019231 \\
\hline s17 & 0.551948 & 0 & 0.712922 & 0.283333 & 0.5 & 0.634615 \\
\hline $\mathrm{s} 18$ & 0.766234 & 1 & 0.570337 & 0.116667 & 0.714286 & 0.153846 \\
\hline
\end{tabular}

In addition, Table 3 demonstrates the results of the implementation of the third step of the proposed model.

Table 3

The summary of the results of Table 3

\begin{tabular}{|c|c|c|c|c|c|c|}
\hline & TC(-) & $\mathrm{SR}(+)$ & $\mathrm{D}(-)$ & NOT(+) & $\mathrm{NB}(+)$ & $\mathrm{SV}(+)$ \\
\hline s1 & 0.474026 & 0.764706 & 0.007002 & 0.55 & 0.785714 & 0.980769 \\
\hline $\mathrm{s} 2$ & 0.571429 & 0.470588 & 0.257798 & 0.433333 & 0.5 & 0.769231 \\
\hline s3 & 0.512987 & 0.882353 & 0.302992 & 0 & 0 & 0.961538 \\
\hline s4 & 0 & 0.705882 & 1 & 1 & 0.714286 & 0.961538 \\
\hline s5 & 0.5 & 0.823529 & 0 & 0.266667 & 0.192857 & 0.557692 \\
\hline s6 & 0.441558 & 0.941176 & 0.00191 & 0.466667 & 0.214286 & 0.480769 \\
\hline s7 & 0.597403 & 0.588235 & 0.742202 & 0.433333 & 1 & 1 \\
\hline s8 & 0.974026 & 0.411765 & 0.474857 & 0.416667 & 0.392857 & 0.557692 \\
\hline s9 & 0.954545 & 0.529412 & 0.256525 & 0.333333 & 0.357143 & 0.807692 \\
\hline $\mathrm{s} 10$ & 0.974026 & 0.647059 & 0.222788 & 0.816667 & 0.785714 & 0 \\
\hline s11 & 0.915584 & 0.117647 & 0.00191 & 0.766667 & 0.714286 & 0.826923 \\
\hline $\mathrm{s} 12$ & 0.967532 & 0.235294 & 0.209421 & 0.183333 & 0 & 0.884615 \\
\hline s13 & 0.655844 & 0.176471 & 0.209421 & 0.916667 & 0.264286 & 0.653846 \\
\hline s14 & 0.837662 & 0.294118 & 0.464036 & 0.35 & 0.214286 & 0.788462 \\
\hline s 15 & 0.720779 & 0.352941 & 0.252705 & 0.533333 & 0.107143 & 0.384615 \\
\hline s16 & 1 & 0.058824 & 0.354551 & 0.866667 & 0.821429 & 0.980769 \\
\hline s17 & 0.448052 & 1 & 0.287078 & 0.716667 & 0.5 & 0.365385 \\
\hline $\mathrm{s} 18$ & 0.233766 & 0 & 0.429663 & 0.883333 & 0.285714 & 0.846154 \\
\hline
\end{tabular}

Finally, Table 4 demonstrates the results of the implementation of grey method as follows,

\section{Table 4}

The priority of different suppliers

\begin{tabular}{|c|c|c|c|c|c|c|c|}
\hline & TC(-) & $\mathrm{SR}(+)$ & $\mathrm{D}(-)$ & $\operatorname{NOT}(+)$ & $\mathrm{NB}(+)$ & $\mathrm{SV}(+)$ & Priority \\
\hline s1 & 0.678414 & 0.566667 & 0.993047 & 0.645161 & 0.56 & 0.504854 & 0.658024 \\
\hline s2 & 0.636364 & 0.68 & 0.79504 & 0.697674 & 0.666667 & 0.565217 & 0.673494 \\
\hline s3 & 0.660944 & 0.53125 & 0.767465 & 1 & 1 & 0.509804 & 0.74491 \\
\hline s4 & 1 & 0.586207 & 0.5 & 0.5 & 0.583333 & 0.509804 & 0.613224 \\
\hline s5 & 0.666667 & 0.548387 & 1 & 0.789474 & 0.838323 & 0.641975 & 0.747471 \\
\hline s6 & 0.693694 & 0.515152 & 0.998094 & 0.681818 & 0.823529 & 0.675325 & 0.731269 \\
\hline s7 & 0.626016 & 0.62963 & 0.573986 & 0.697674 & 0.5 & 0.5 & 0.587884 \\
\hline s8 & 0.506579 & 0.708333 & 0.678032 & 0.705882 & 0.717949 & 0.641975 & 0.659792 \\
\hline s9 & 0.511628 & 0.653846 & 0.795846 & 0.75 & 0.736842 & 0.553191 & 0.666892 \\
\hline s10 & 0.506579 & 0.607143 & 0.817803 & 0.550459 & 0.56 & 1 & 0.673664 \\
\hline s11 & 0.522034 & 0.894737 & 0.998094 & 0.566038 & 0.583333 & 0.547368 & 0.685267 \\
\hline $\mathrm{s} 12$ & 0.508251 & 0.809524 & 0.826842 & 0.84507 & 1 & 0.530612 & 0.753383 \\
\hline s13 & 0.603922 & 0.85 & 0.826842 & 0.521739 & 0.79096 & 0.604651 & 0.699686 \\
\hline s14 & 0.54417 & 0.772727 & 0.683043 & 0.740741 & 0.823529 & 0.55914 & 0.687225 \\
\hline s15 & 0.581132 & 0.73913 & 0.798272 & 0.652174 & 0.903226 & 0.722222 & 0.732693 \\
\hline s16 & 0.5 & 0.944444 & 0.738252 & 0.535714 & 0.54902 & 0.504854 & 0.628714 \\
\hline s17 & 0.690583 & 0.5 & 0.776954 & 0.582524 & 0.666667 & 0.732394 & 0.658187 \\
\hline $\mathrm{s} 18$ & 0.810526 & 1 & 0.699466 & 0.530973 & 0.777778 & 0.541667 & 0.726735 \\
\hline$w j$ & 0.166667 & 0.166667 & 0.166667 & 0.166667 & 0.166667 & 0.166667 & \\
\hline
\end{tabular}


In summary, the order of suppliers can be specified as follows,

$\mathrm{S} 12>\mathrm{S} 5>\mathrm{S} 3>\mathrm{S} 15>\mathrm{S} 6>\mathrm{S} 18>\mathrm{S} 13>\mathrm{S} 14>\mathrm{S} 11>\mathrm{S} 10>\mathrm{S} 2>\mathrm{S} 9>\mathrm{S} 8>\mathrm{S} 17>\mathrm{S} 1>\mathrm{S} 16>\mathrm{S} 4>\mathrm{S} 7$.

\section{Conclusion}

In this paper, we have presented a new mixed integer multi-objective programming technique to determine the level of order materials from various suppliers. The proposed model of this paper uses grey method to rank different suppliers in terms of various attributes and using the proposed mix integer programming technique it is possible to determine the desirable level of inventory ordered from each supplier. The proposed model of this paper can be extended for problems that are more realistic. In addition, for large-scale problems, it is possible to use multi-objective metaheuristics methods to generate Pareto-optimal solutions and we leave it for interested researchers as future studies.

\section{References}

Albino, V., Garavelli, A. C., \& Gorgoglione, M. (1998). Fuzzy logic in vendor rating: a comparison between a fuzzy logic system and a neural network. Fuzzy Economic Review, 3(2), 25-47.

De Boer, L., Van der Wegen, L., \& Telgen, J. (1998). Outranking methods in support of supplier selection. European Journal of Purchasing and Supply Management, 4, 109-118.

De Boer, L., Labro, E., \& Morlacchi, P. (2001). A review of methods supporting supplier selection. European Journal of Purchasing \& Supply Management, 7(2), 75-89.

Deng, J. L. (1989). Introduction to grey system theory. The Journal of grey system, 1(1), 1-24.

Ghodsypour, S. H., \& O'brien, C. (2001). The total cost of logistics in supplier selection, under conditions of multiple sourcing, multiple criteria and capacity constraint. International Journal of Production Economics, 73(1), 15-27.

Kahraman, C., Cebeci, U., \& Ulukan, Z. (2003). Multi-criteria supplier selection using fuzzy AHP. Logistics Information Management, 16(6), 382-394.

Min, H. (1994). International supplier selection:: A multi-attribute utility approach. International Journal of Physical Distribution \& Logistics Management, 24(5), 24-33.

Noorul Haq, A., \& Kannan, G. (2006). Design of an integrated supplier selection and multi-echelon distribution inventory model in a built-to-order supply chain environment. International Journal of Production Research, 44(10), 1963-1985.

Pan, A. C. (1989). Allocation of order quantity among suppliers. Journal of Purchasing and Materials Management, 25(3), 36-39.

Pi, W. N., \& Low, C. (2006). Supplier evaluation and selection via Taguchi loss functions and an AHP. The International Journal of Advanced Manufacturing Technology, 27(5-6), 625-630.

Rosenthal, E. C., Zydiak, J. L., \& Chaudhry, S. S. (1995). Vendor Selection with Bundling. Decision Sciences, 26(1), 35-48.

Saen, R. F. (2008). Supplier selection by the new AR-IDEA model. The International Journal of Advanced Manufacturing Technology, 39(11-12), 1061-1070.

Saen, R. F. (2009). A decision model for ranking suppliers in the presence of cardinal and ordinal data, weight restrictions, and nondiscretionary factors. Annals of Operations Research, 172(1), 177-192.

Shin, H., Collier, D. A., \& Wilson, D. D. (2000). Supply management orientation and supplier/buyer performance. Journal of Operations Management, 18(3), 317-333.

Talluri, S., \& Baker, R. C. (2002). A multi-phase mathematical programming approach for effective supply chain design. European Journal of Operational Research, 141(3), 544-558.

Wang, G., Huang, S. H., \& Dismukes, J. P. (2004). Product-driven supply chain selection using integrated multi-criteria decision-making methodology. International journal of production economics, 91(1), 1-15. 
1832

Wangphanich, P., Kara, S., \& Kayis, B. (2010). Analysis of the bullwhip effect in multi-product, multi-stage supply chain systems-a simulation approach. International Journal of Production Research, 48(15), 4501-4517.

Weber, C. A., Current, J. R., \& Benton, W. C. (1991). Vendor selection criteria and methods. European journal of operational research, 50(1), 2-18.

Wray, B., Palmer, A., \& Bejou, D. (1994). Using neural network analysis to evaluate buyer-seller relationships. European Journal of Marketing, 28(10), 32-48.

$\mathrm{Wu}, \mathrm{H}$. H. (2002). A comparative study of using grey relational analysis in multiple attribute decision making problems. Quality Engineering, 15(2), 209-217. 